\title{
AMENDMENTS
}

\section{Author Correction: Miniature gold nanorods for photoacoustic molecular imaging in the second near-infrared optical window}

Yun-Sheng Chen (iD, Yang Zhao (D), Soon Joon Yoon, Sanjiv Sam Gambhir (iD and Stanislav Emelianov (D)

Correction to: Nature Nanotechnology https://doi.org/10.1038/s41565-019-0392-3, published online 4 March 2019.

In the version of this Article originally published, the right side of Fig. $4 \mathrm{j}$ and the left side of Fig. $5 \mathrm{~b}$ were duplicates of other panels; these have been replaced with the correct panels. The original and corrected figures are shown below.

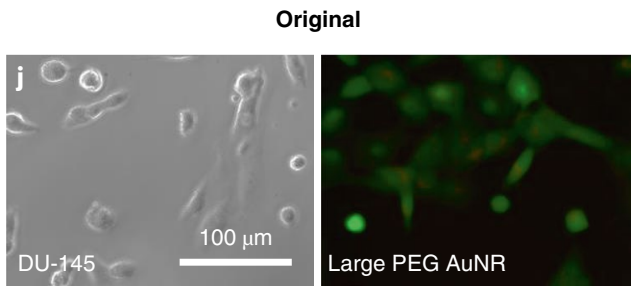

Corrected

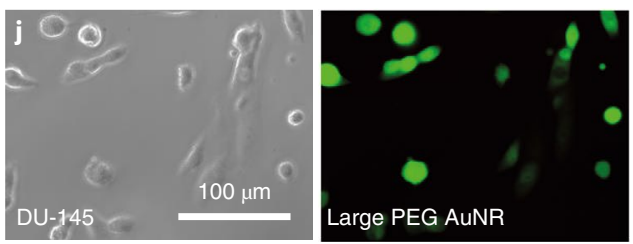

Fig. 4 | Orginal and Corrected.

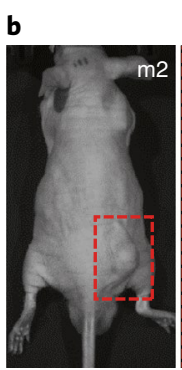

Original
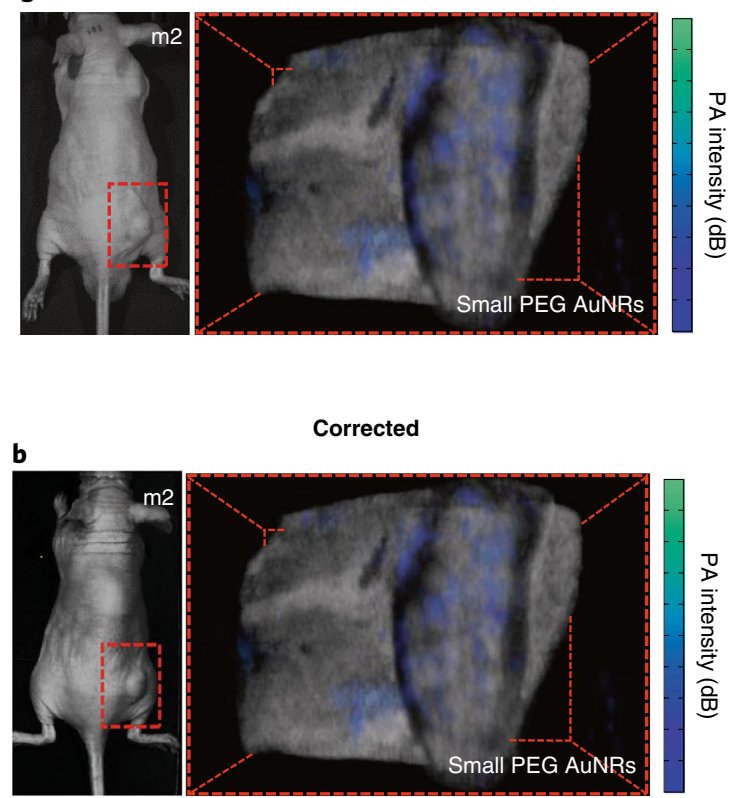

Corrected

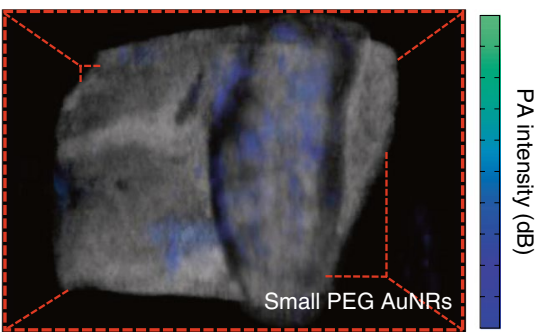

Fig. 5 | Orginal and Corrected. 